\title{
Clinical significance of respiratory bronchiolitis on open lung biopsy and its relationship to smoking related interstitial lung disease
}

\author{
James Moon, Ronald M du Bois, Thomas V Colby, David M Hansell,
} Andrew G Nicholson

\begin{abstract}
Background-Respiratory bronchiolitisassociated interstitial lung disease (RBILD) is a rare form of interstitial lung disease which may present in similar fashion to other types of chronic interstitial pneumonia. The purpose of this study was to undertake a clinicopathological review of 10 patients with RBILD and to examine the clinical and imaging data related to its histopathological pattern, in particular the relationship of RBILD to smoking.
\end{abstract}

Methods-Thirteen out of 168 retrospectively reviewed patients, from whom biopsy specimens were taken for suspected diffuse lung disease, were identified with a histopathological pattern of RBILD. Three cases were rejected as follow up data were unavailable. The 10 remaining cases constituted the study group and both clinical and imaging data were collected from patients' notes and referring physicians.

Results-Histopathologically, four cases of RBILD overlapped with the pattern of desquamative interstitial pneumonitis (DIP) and nine also had microscopic evidence of centrilobular emphysema. Nine patients were smokers, ranging from 3 to 80 pack years. The one non-smoker had an occupational exposure to the fumes of solder flux. The sex distribution was equal with an age range of 32-65 years. Two patients were clubbed. Lung function tests showed both restrictive and obstructive patterns together with severe reductions in carbon monoxide transfer factor in seven patients. Chest radiographs showed reticular or reticulonodular infiltrates in five patients and a ground glass pattern in two. CT scans were consistent with either DIP or RBILD in six of eight patients. Although seven patients remained stable or improved, either with or without treatment, three patients deteriorated.

Conclusions-This study adds weight to the hypothesis that smoking can cause clinically significant interstitial lung disease, with deterioration in pulmonary function despite treatment. Given the overlapping histopathological patterns of RBILD and DIP and their strong association with smoking, the term "smoking related interstitial lung disease" is suggested for those patients who are smokers. (Thorax 1999;54:1009-1014)

Keywords: interstitial lung disease; smoking; respiratory bronchiolitis-associated interstitial lung disease (RBILD)
In 1974 Niewoehner et al described inflammatory changes in the peripheral airways of young, previously healthy patients who had died suddenly from non-hospital deaths. These changes were strongly associated with a history of smoking. ${ }^{1}$ The characteristic lesion was described as a respiratory bronchiolitis associated with the presence of tan brown pigmented macrophages in respiratory bronchioles spilling into neighbouring alveoli. Strictly peribronchiolar alveolar septal thickening characteristically radiating in a stellate fashion from the bronchiole was also present. Subsequent papers, based

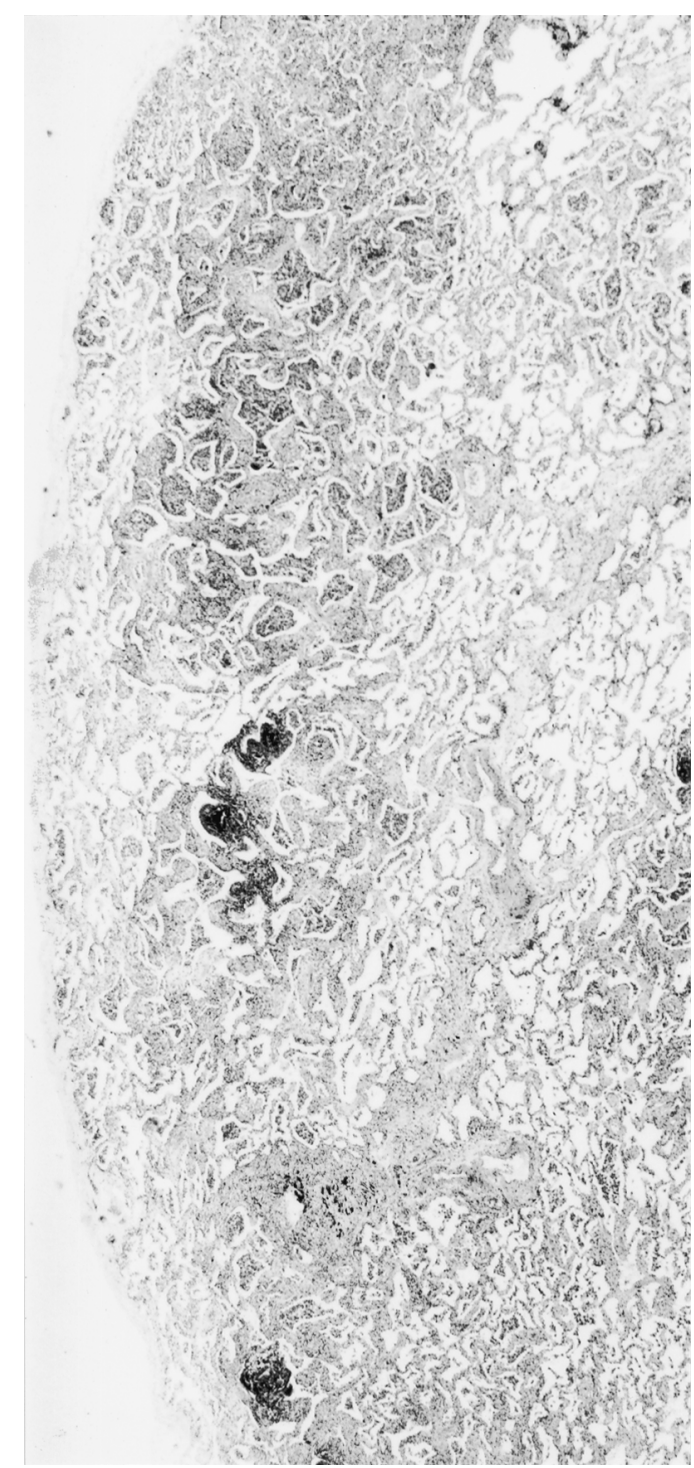

Figure 1 Low power view of respiratory bronchiolitis showing the patchy centrilobular distribution which differentiates the pattern from desquamative interstitial pneumonitis. 


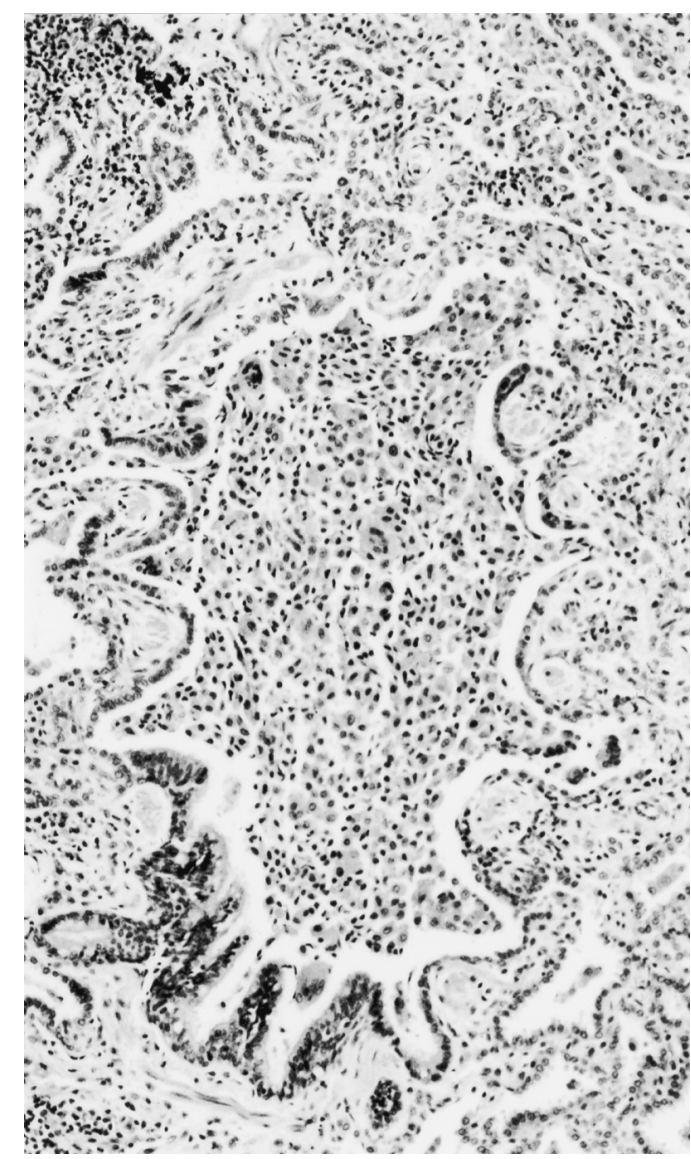

Figure 2 Bronchiole and adjacent alveoli containing mildly pigmented alveolar macrophages, most concentrated within the airway lumen. There is also focal peribronchiolar inflammation and fibrosis.

on necropsy findings, have documented a relationship between peribronchiolar fibrosis/ inflammation and smoking. ${ }^{2}$

Even before the study by Niewoehner et al, subtle abnormalities in lung function occurring within five years of starting to smoke had been documented in teenagers ${ }^{4}$ but they were not believed to be a cause of clinically significant pulmonary dysfunction. However, in 1986 Myers et al described six patients who had

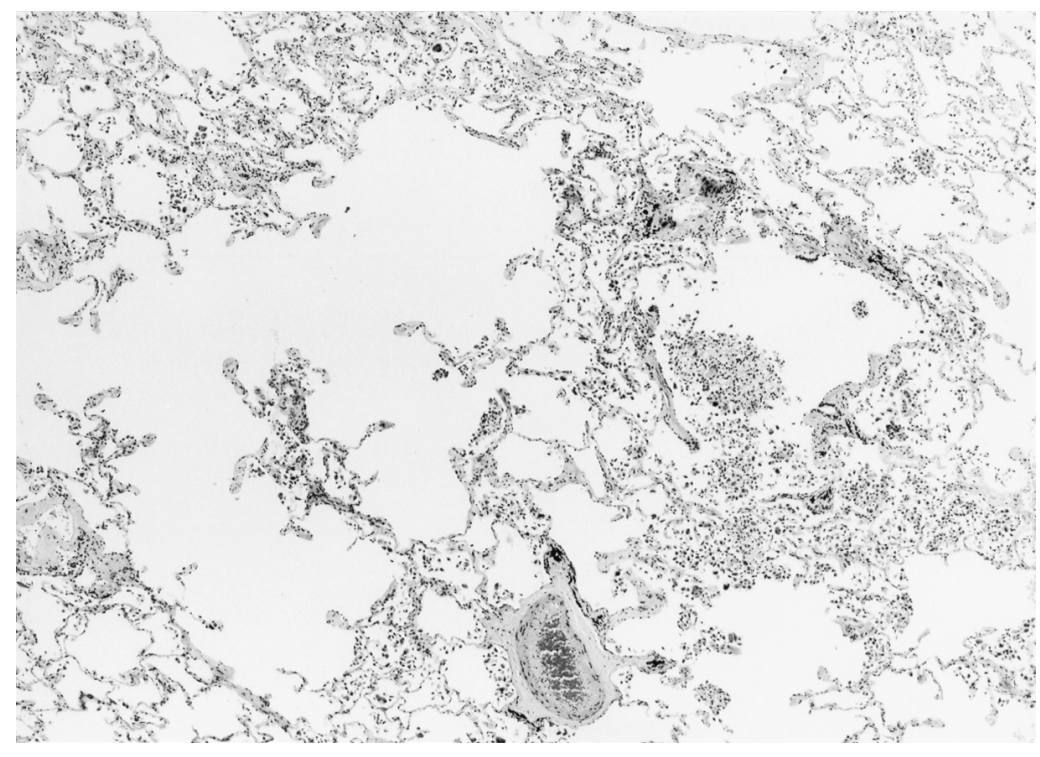

Figure 3 Respiratory bronchiolitis and co-existent early centrilobular emphysema. As well as focal loss of alveolar architecture, macrophages remain concentrated within the bronchiole, although there is little peribronchiolar inflammation and fibrosis. clinical and/or radiographic abnormalities suggestive of interstitial lung disease with respiratory bronchiolitis as the only histopathological lesion in the biopsy specimens, this evidence suggesting that respiratory bronchiolitis was the cause of the clinical findings. ${ }^{5}$ The disease ran a benign course, even in two symptomatic patients who did not receive treatment. The authors also stressed that care was needed to distinguish the histopathology of respiratory bronchiolitis from idiopathic pulmonary fibrosis, desquamative interstitial pneumonitis (DIP), and changes related to inhalation of mineral dusts. The term "respiratory bronchiolitis-associated interstitial lung disease" (RBILD) was subsequently coined in a further series that clarified the histopathological differences between the incidental changes of smoking, RBILD, and DIP, a key feature being the extent of interstitial inflammation. ${ }^{6}$

The current literature suggests that respiratory bronchiolitis is a histopathological pattern which overlaps with the pattern of DIP and enters the differential diagnosis of idiopathic pulmonary fibrosis. ${ }^{7}$ We have reviewed our open lung biopsy specimens taken for suspected diffuse lung disease between 1980 and 1998 in order to evaluate the clinical and imaging findings related to this particular histopathological pattern and to investigate its associations.

\section{Methods}

One hundred and sixty eight open or videoassisted lung biopsy specimens in the files of the Royal Brompton Hospital taken for investigation of diffuse lung disease between 1980 and 1998 were independently reviewed by two pulmonary histopathologists without knowledge of the previous histopathological diagnosis or clinical data. Where independent classification differed between the pathologists, a consensus opinion was reached after further joint review in the context of the clinical history. All sections had been routinely stained with haematoxylin and eosin, with additional staining using elastin-van Gieson stains.

In 13 of the cases respiratory bronchiolitis was the predominant histopathological pattern. A 14th case was rejected as respiratory bronchiolitis was seen in addition to a pattern of usual interstitial pneumonitis, the latter being considered the dominant pathology. A further three cases were rejected as follow up data were unavailable. Of the 10 remaining cases, only the three most recent cases had been diagnosed as RBILD, with six cases originally classified as consistent with cryptogenic fibrosing alveolitis in an early/cellular or DIP-like phase and one case as DIP.

Clinical data, including history of previous exposures, chronic disease, drugs and clinical examination, were collected for the remaining 10 cases, either from the patients' notes or from general practitioners; in particular, potential causes of bronchiolitis other than smoking were sought and excluded. In all cases lung function measurements had been performed at presentation and during the follow up period, and included forced expiratory volume in one 
Table 1 Clinical data

\begin{tabular}{|c|c|c|c|c|c|c|c|c|c|c|}
\hline & \multicolumn{10}{|c|}{ Case no. } \\
\hline & 1 & 2 & 3 & 4 & 5 & 6 & 7 & 8 & 9 & 10 \\
\hline Age at onset (years) & 65 & 60 & 32 & 58 & 42 & 40 & 35 & 33 & 61 & 45 \\
\hline Sex & $\mathrm{F}$ & M & $\mathrm{F}$ & M & $\mathrm{M}$ & $\mathrm{F}$ & $\mathrm{F}$ & M & M & $\mathrm{F}$ \\
\hline Smoking (pack years) & 30 & 80 & 17 & 64 & 13 & 3 & 0 & 60 & 67 & 21 \\
\hline Quit at presentation & No & No & No & 1 year & 1 year & 2 years & Non-smoker & No & No & No \\
\hline Occupational exposure & No & No & No & No & No & No & Solder & No & Wood dust & No \\
\hline Relevant PMH & No & No & Scleroderma & No & CREST & Scleroderma & No & No & No & No \\
\hline \multicolumn{11}{|l|}{ Symptoms } \\
\hline SOB & Yes & No & No & Yes & No & Yes & Yes & Yes & Yes & Yes \\
\hline Cough & Yes & No & No & No & No & No & No & Yes & Yes & No \\
\hline Sputum & No & No & No & No & No & No & No & No & No & No \\
\hline Haemoptysis & Yes & No & No & No & No & Yes & No & No & No & No \\
\hline $\begin{array}{l}\text { Chest } \\
\text { pain/discomfort }\end{array}$ & No & Yes & No & No & No & No & Yes & No & No & Yes \\
\hline Fever/weight loss & No & No & No & No & No & No & No & Yes & Yes & No \\
\hline Basal crackles & Yes & No & No & Yes & Yes & Yes & Yes & Yes & No & No \\
\hline Clubbing & Yes & No & No & No & No & No & No & No & Yes & No \\
\hline Other & & & Screened ${ }^{\star}$ & & Screened ${ }^{\star}$ & & & & & \\
\hline
\end{tabular}

$\mathrm{PMH}=$ past medical history; $\mathrm{SOB}=$ shortness of breath

$\star$ Patients with scleroderma found to have reduced transfer factor.

second $\left(\mathrm{FEV}_{1}\right)$, forced vital capacity (FVC), total lung capacity (TLC), carbon monoxide transfer factor (TLCO), and carbon monoxide transfer coefficient (KCO). Results were expressed as percentages of values predicted from the subjects' age, sex and height. Throughout the study period lung volumes were measured using an Ohio water sealed spirometer (Ohio Instruments, Atlanta, Georgia, USA). TLC was measured in a whole body plethysmograph (Fenyves and Gut, Basel, Switzerland). Measures of gas transfer (TLCO, KCO) were made by the single breath technique using a $\mathrm{P} \mathrm{K}$ Morgan respirometer (P K Morgan, Chatham, Kent, UK). The criteria used to define significant changes in the pulmonary function tests during the follow up were identical to those used in previous studies ${ }^{8}{ }^{9}$ - namely, improvement $=$ a rise of more than $15 \%$ from baseline values of either FVC or TLCO; stability (no change) $=$ no changes or changes of $\pm 15 \%$ from baseline values; deterioration $=$ a decline of more than $15 \%$ from baseline values.

Computed tomographic (CT) scans were performed on an electron beam CT machine (Imatron Inc, San Francisco, California, USA) or an Elscint 3003 CT scanner (Elscint Inc, Haifa, Israel). All patients had $1.5 \mathrm{~mm}$ or $3 \mathrm{~mm}$ sections obtained at full inspiration. All patients were scanned supine at full inspiration. In some cases additional expiratory films and prone sections were taken. Images were photographed at window settings appropriate for viewing the lung parenchyma $(-500 \mathrm{HU}$ centre, $1500 \mathrm{HU}$ width) The scans, together with plain chest radiographs, were assessed retrospectively by a pulmonary radiologist and the

Table 2 Lung function data

\begin{tabular}{|c|c|c|c|c|c|c|c|c|c|c|}
\hline & \multicolumn{10}{|c|}{ Case no. } \\
\hline & 1 & 2 & 3 & 4 & 5 & 6 & 7 & 8 & 9 & 10 \\
\hline $\mathrm{FEV}_{1}$ & 89 & 101 & 111 & 77 & 85 & 89 & 97 & 54 & 103 & 47 \\
\hline FVC & 109 & 114 & 121 & 75 & 89 & 115 & 86 & 54 & 99 & 49 \\
\hline $\mathrm{FEV}_{1} / \mathrm{FVC}$ & 68 & 76 & 80 & 82 & 78 & 67 & 87 & 78 & 67 & 81 \\
\hline TLC & 87 & 114 & 115 & 71 & 87 & 119 & 78 & 61 & 89 & 73 \\
\hline Theo & 44 & 90 & 61.3 & 55 & 55 & 78 & 59 & 45 & 52 & 31 \\
\hline KCO & 55 & 76 & 100 & 106 & 72 & 73 & 77 & 87 & 82 & 51 \\
\hline
\end{tabular}

All values are percentage predicted.

$\mathrm{FEV}_{1}=$ forced expiratory volume in one second $; \mathrm{FVC}=$ forced vital capacity; TLC = total lung capacity; TLCO = carbon monoxide transfer factor; $\mathrm{KCO}=$ carbon monoxide transfer coefficient. presence or absence of patchy ground glass pattern, reticular pattern, emphysema, honeycombing, airways distortion, and bronchial wall thickening on the high resolution CT (HRCT) scan were recorded.

\section{Results}

All 10 cases showed the histopathological features of respiratory bronchiolitis with a predominantly peribronchiolar distribution of alveolar macrophages in six cases (figs 1 and 2), the features being more widespread in four cases and overlapping with DIP. Peribronchiolar fibrosis was present in all cases and mild peribronchiolar chronic inflammation was noted in nine cases. Features of early centrilobular emphysema (fig 3) were also seen in these nine cases.

\section{CLINICAL FEATURES}

The clinical features of the patient population are shown in table 1 . There were five men and five women with ages ranging between 32 and 65 years. All except one had been smokers, the amount smoked ranging from 3 to 80 pack years and, of these, three had given up at one, one, and two years prior to presentation. The non-smoker had been exposed to the fumes of solder flux in her employment. One of the other nine patients had additional exposure to smoke carcinogens from employment in the production and development of cigarettes, and one patient had additional exposure to wood dust. Three of the 10 patients had systemic sclerosis.

Eight of the 10 patients were symptomatic at presentation, with breathlessness being the commonest symptom followed by cough, haemoptysis, chest discomfort, and systemic symptomatology (table 1). Two of the three patients with systemic sclerosis had their lung disease identified on routine lung investigation. On examination, two patients exhibited digital clubbing. One of these also had basal crackles, as did five individuals who did not have digital clubbing.

Lung function tests, shown in table 2, showed a restrictive ventilatory defect in four patients, airflow obstruction in three, and an isolated gas transfer deficit in three. Severe 


\begin{tabular}{|c|c|c|c|c|c|c|c|c|c|c|}
\hline & \multicolumn{10}{|l|}{ Case no. } \\
\hline & 1 & 2 & 3 & 4 & 5 & 6 & 7 & 8 & 9 & 10 \\
\hline \multicolumn{11}{|l|}{ CT } \\
\hline Patchy ground glass & Yes & Yes & No & Yes & No & Yes & Yes & & & Yes \\
\hline Reticular pattern & Yes & Yes & No & Yes & Yes & Yes & No & & & Yes \\
\hline Emphysema & Yes & No & Yes & No & No & No & No & & & Yes \\
\hline Basal honeycombing & No & No & No & No & Yes & No & No & & & No \\
\hline Airways dilatation & No & Yes & No & Yes & No & No & No & & & No \\
\hline Bronchial wall thickening & No & No & No & No & Yes & No & No & & & No \\
\hline \multirow[t]{2}{*}{ Favoured HRCT diagnoses } & 1. RBILD & 1. RBILD & 1. & 1. DIP & 1. Limited & 1. DIP & 1. DIP & & & 1. DIP \\
\hline & 2. UIP & & Emphysema & 2. UIP & UIP & & & & & 2. UIP \\
\hline \multirow[t]{2}{*}{ Chest radiography pattern } & Retic/nodular & Retic/nodular & Normal & Reticular & Retic/nodular & Normal & Ground glass & Reticular & $\begin{array}{l}\text { Ground } \\
\text { glass }\end{array}$ & $\begin{array}{l}\text { Ground } \\
\text { glass }\end{array}$ \\
\hline & & & & & & & $\begin{array}{l}\text { Subsegmental } \\
\text { collapse }\end{array}$ & & Nodules & Nodules \\
\hline
\end{tabular}

RBILD = respiratory bronchiolitis-associated interstitial lung disease; UIP = usual interstitial pneumonitis; DIP = desquamative interstitial pneumonitis.

reductions in vital capacity (less than $60 \%$ predicted) were seen in two of these seven patients. In general, the degree of airflow obstruction was mild. Severe reductions in TLCO (less than $60 \%$ predicted) were observed in seven of the 10 patients, two of whom had systemic sclerosis.

The imaging features are shown in table 3. Chest radiography was normal in two patients. In the remainder there was reticular or reticu-

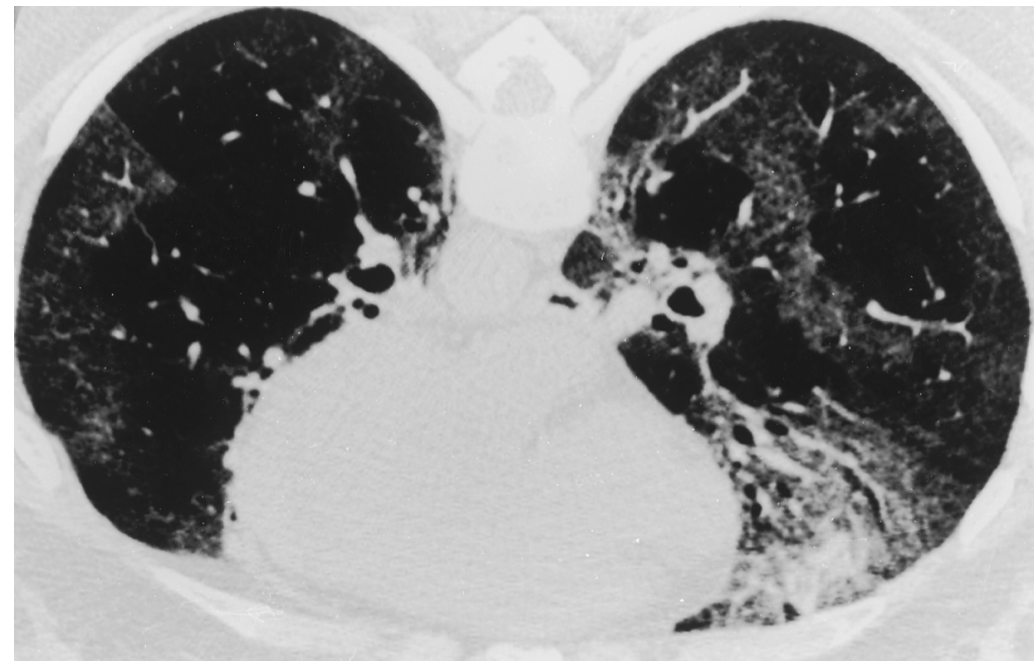

Figure 4 Thin section CT scan through the lower lobes of patient 1 showing patchy ground glass opacification and thickening of a few interlobular septa.

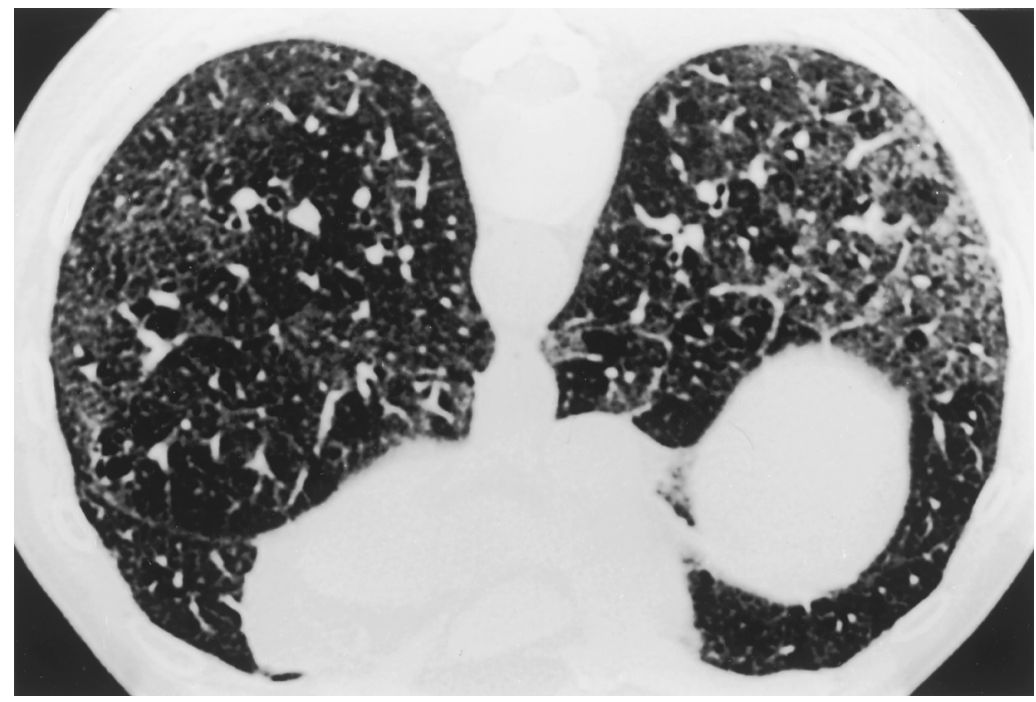

Figure 5 Thin section CT scan through the lung bases of patient 2 showing a fine intralobular reticular pattern including some thickened interlobular septa. There are also areas of ground glass opacification and some dilatation of the bronchi. lonodular shadowing in five which was basal in two patients, widespread in two, and mid and lower zone in one. In three patients the pattern was predominantly ground glass with additional nodular shadowing in two and subsegmental collapse in one. Eight of the 10 patients also had chest CT scans available for review. Five of the eight had both patchy ground glass changes and reticular patterns (figs 4 and 5), with a sixth having only ground glass changes. The features in these six cases were considered to be most consistent with either respiratory bronchiolitis or DIP, two of these patients also showing emphysematous changes. One patient had emphysematous changes only on review of the CT scan, and one patient had a reticular pattern with basal peripheral honeycombing, favouring a diagnosis of usual interstitial pneumonitis.

In nine of the 10 patients a diagnosis of smoking related interstitial lung disease was proposed on the basis of interpreting the histopathological findings in the light of clinical and radiological data. In patient 9 a diagnosis of RBILD associated with an occupational exposure was made.

Treatment and follow up are summarised in table 4 . Of the six patients who had not quit cigarette smoking at the time of presentation, five quit after diagnosis although one patient continued to smoke a pipe. One patient is still smoking. Seven of the 10 patients were treated with prednisolone, alone in one patient and with immunosuppression (azathioprine or cyclophosphamide) in the other six patients. The patient treated solely with prednisolone had a sustained improvement in both FVC and TLCO. Of the six patients treated with prednisolone and immunosuppression, FVC was unchanged in five patients and deteriorated in one; TLCO improved in one patient, deteriorated in two, and was unchanged in three. In the three patients who received no treatment, FVC increased in one. The other lung indices were unchanged in all three patients. Of the three patients with scleroderma, two showed stable lung function following treatment with prednisolone and cyclophosphamide and the third patient had a fall in gas transfer despite treatment. This patient was the one who continued to smoke after diagnosis. 
Table 4 Treatment and follow up data

\begin{tabular}{|c|c|c|c|c|c|c|c|c|c|c|}
\hline & \multicolumn{10}{|c|}{ Case no. } \\
\hline & 1 & 2 & 3 & 4 & 5 & 6 & 7 & 8 & 9 & 10 \\
\hline Quit smoking after diagnosis & Yes & Yes & No & Already quit & Already quit & Already quit & Non-smoker & Yes $^{\star}$ & Yes & Yes \\
\hline Treatment & None & None & $\begin{array}{l}\text { Pred } \\
\text { CP }\end{array}$ & $\begin{array}{l}\text { Pred } \\
\text { CP } \\
\text { AZT }\end{array}$ & $\begin{array}{l}\text { Pred } \\
\text { CP }\end{array}$ & $\begin{array}{l}\text { Pred } \\
\text { CP }\end{array}$ & $\begin{array}{l}\text { Pred } \\
\text { CP }\end{array}$ & Pred & $\begin{array}{l}\text { Pred } \\
\text { CP }\end{array}$ & None \\
\hline $\begin{array}{l}\text { Follow up (months) } \\
\text { Changes in lung function: }\end{array}$ & 21 & 20 & 56 & 60 & 56 & 20 & 123 & 29 & 89 & 6 \\
\hline $\begin{array}{l}\text { FVC } \\
\text { TLCO }\end{array}$ & $\begin{array}{l}\mathrm{NC} \\
\mathrm{NC}\end{array}$ & $\begin{array}{l}\mathrm{NC} \\
\mathrm{NC}\end{array}$ & $\begin{array}{l}\mathrm{NC} \\
\mathrm{D}\end{array}$ & $\begin{array}{l}\mathrm{D} \\
\mathrm{NC}\end{array}$ & $\begin{array}{l}\mathrm{NC} \\
\mathrm{NC}\end{array}$ & $\begin{array}{l}\mathrm{NC} \\
\mathrm{NC}\end{array}$ & $\begin{array}{l}\mathrm{NC} \\
\mathrm{I}\end{array}$ & $\begin{array}{l}\text { I } \\
\text { I }\end{array}$ & $\begin{array}{l}\mathrm{NC} \\
\mathrm{D}\end{array}$ & $\begin{array}{l}\mathrm{I} \\
\mathrm{NC}\end{array}$ \\
\hline
\end{tabular}

Pred = prednisolone; $\mathrm{CP}=$ cyclophosphamide; $\mathrm{AZT}=$ azathioprine.

Changes in lung function defined as $>15 \%$ change from baseline values: $\mathrm{I}=$ improved, $\mathrm{D}=$ deteriorated, $\mathrm{NC}=$ no change.

${ }^{\star}$ Continued to smoke a pipe.

\section{Discussion}

Despite frequent abnormalities in pulmonary function tests $^{4}$ and abnormal chest radiographic and CT findings in "asymptomatic" smokers, ${ }^{10-13}$ it is rare for changes to be severe enough to warrant clinical presentation as an interstitial lung disease, although biopsy specimens have been taken from occasional cases after incidental discovery of an abnormal radiograph. ${ }^{5}{ }^{6}$ Respiratory bronchiolitis is usually an incidental finding in specimens resected for carcinoma or at necropsy; indeed, its first description by Niewoehner et al was a necropsy study of young adults looking for changes in the peripheral airways. ${ }^{1}$ This is supported by the comparatively few reports in the literature of respiratory bronchiolitis presenting with suspected interstitial lung disease. ${ }^{56}$

Based on the two major published series totalling 24 patients, ${ }^{56}$ RBILD presents in patients aged $22-53$ years and with equal sex distribution. All patients smoked, with mean pack years of 32 and 39, respectively, in the two series. The commonest presenting features were dyspnoea and a sometimes productive cough. No patients were clubbed. The chest radiographs were either normal or showed fine reticular or reticular nodular shadowing. In the paper by Myers et al one patient had severe ( $<60 \%$ predicted) reduction in FVC and three of the patients had a TLCO of $<60 \%$ predicted. ${ }^{5}$ In the study by Yousem et al mean data are presented but in no patient was TLCO $>80 \%$ predicted and it was as low as $40 \%$ in at least one patient. The lowest FVC was $47 \%$ predicted. ${ }^{6}$

The findings in our series show a mixture of histopathological features, the most striking of which was accumulation of pigmented macrophages in the region of respiratory bronchioles. In four cases the distribution of macrophages was more widespread and overlapped with the pattern of DIP, but the additional presence of peribronchiolar inflammation and fibrosis favoured classification of the findings as respiratory bronchiolitis. These changes are similar to those described in previous series although nine of our 10 cases also had microscopic evidence of centrilobular emphysema. The clinical data at presentation also mirror those seen in other series, with the commonest presenting symptoms being dyspnoea and cough, although two patients also had haemoptysis. Clubbing was present in two of our patients, not previously described in RBILD, and it is therefore important to recognise that this clinical sign is not specific to cryptogenic fibrosing alveolitis in the context of diffuse lung disease. Indeed, clubbing may rarely be seen in association with several other chronic diffuse lung diseases. One patient did not smoke cigarettes but did have an occupational exposure to solder flux which was thought to be the cause of her pathology. Pulmonary function tests showed mainly restrictive lung function, all but one patient having a reduced TLCO which was less than $60 \%$ predicted in six cases. Less dramatic changes were seen in FVC.

Radiographic features were also similar to those seen in previous series, with the HRCT scan being consistent with either respiratory bronchiolitis or DIP in the majority of cases. One previous series of HRCT findings in five patients with RBILD described a range of abnormalities ranging from normal to extensive pan-lobular ground glass opacities. Emphysema was also noted in one case. ${ }^{14}$ Our findings are not dissimilar to those seen in a series of radiographic abnormalities found in "healthy" volunteers who smoke, with chest radiographic changes including increased nodular densities and peribronchial cuffing, and CT scans demonstrating subtle parenchymal abnormalities including ground glass changes even in asymptomatic smokers with normal lung function. ${ }^{13}$ This is mirrored in a series of patients who were heavy smokers (mean 41 pack years) undergoing lung surgery for coin lesions and assessed for parenchymal changes by CT scanning. Ground glass changes, subpleural micronodules, and emphysema were all frequently identified, the first two abnormalities correlating with pathological findings of accumulation of macrophages plus mild inflammation/fibrosis in alveolar walls and peribronchiolar macrophages, respectively. ${ }^{12}$ Thus, as with histopathological changes, ${ }^{1}$ the incidence of $\mathrm{CT}$ abnormalities attributable to a pattern of respiratory bronchiolitis is much greater than the frequency of patients presenting with symptoms of suspected interstitial lung disease. It is probable that subclinical functional changes identified in young smokers ${ }^{4}$ may well be attributable to such abnormalities.

Seven of the 10 patients either remained stable or showed improvement in their pulmonary function tests, one patient subsequently dying of an unassociated disease. However, three patients showed deterioration in either 
their TLCO or FVC despite treatment. Although one patient continued to smoke, deterioration in the other two cases is in contrast to all published data on patients presenting with RBILD who have either improved or remained stable as a result of smoking cessation or treatment with steroids. ${ }^{7}$ Our cases may reflect true progression of smoking related interstitial lung disease/RBILD but, given the high incidence of subclinical respiratory bronchiolitis in smokers, it is also possible that the presence of respiratory bronchiolitis as the sole pathology in the biopsy specimens was a finding either unrelated or only partially related to the presenting symptoms. In case 3 , in particular, where there was a history of scleroderma and no symptoms at presentation, the decrease in TLCO may reflect scleroderma associated pulmonary disease rather than changes related to smoking. Conversely, given her continued smoking and the lack of progression in patients 5 and 6 , not all interstitial lung diseases classified as collagen vascular disease may necessarily be related to the systemic disorder. This emphasises the importance of taking into account the clinical and radiological findings when assessing the histopathological pattern at lung biopsy, as the presence of respiratory bronchiolitis as the sole finding may be the result of inadequate sampling and may not necessarily predict benign disease. However, despite these reservations, it does seem likely that the histopathological findings at open lung biopsy were responsible for the symptoms in most of our patients.

Cigarette smoking as a cause of emphysema and obstructive lung disease is well established ${ }^{15}$ and nine of our 10 cases showed microscopic evidence of early emphysema. The microscopic evidence of alveolar wall destruction in the presence of respiratory bronchiolitis strengthens the argument that respiratory bronchiolitis may be a precursor to centrilobular emphysema, as postulated in Niewoehner's original paper, ${ }^{1}$ with the accumulation and degeneration of macrophages in the region of the respiratory bronchiole perhaps in part responsible for the centrilobular destruction of alveolar architecture. Cessation of smoking at the time of presentation does not necessarily argue against the diagnosis, as a study of incidentally removed lung during surgery for coin lesions found no decrease in the histopathological damage if the patients had given up smoking. ${ }^{16}$

Smoking as a cause of interstitial lung disease is less well known. The evidence is overwhelming that smoking is associated with Langerhans' cell histiocytosis, a condition in which almost all patients are current or past smokers ${ }^{17}$ and which may go into remission with cessation of smoking. However, the concept of RBILD and DIP being overlapping histopathological patterns that are predominantly related to smoking is less well recognised. In our study four cases were noted to overlap with DIP, a finding already described by Yousem et al. ${ }^{6}$ This, together with the fact that at least $85 \%$ of patients with DIP and nearly all reported cases of RBILD are smokers, has led us to the suggested term "smoking related interstitial lung disease" which would include Langerhans' cell histiocytosis, RBILD, and DIP. We also emphasise that the distinction between RBILD and DIP is histopathologically quite arbitrary, being dependent on the field of focus. This is distinct from the relationship between smoking and usual interstitial pneumonitis where smoking is an independent risk factor ${ }^{18}$ but lacks the high degree of correlation as in the entities discussed above.

In conclusion, this study adds weight to the hypothesis that smoking can rarely be the cause of clinically significant interstitial lung disease, and the term "smoking related interstitial lung disease" is suggested for the overlapping histopathological features seen in these patients. However, it should be noted that not all cases of RBILD occur in smokers, ${ }^{1}$ and inhalation of other noxious substances may rarely be responsible for clinical presentation as diffuse lung disease as was seen in one of our patients.

1 Niewoehner DE, Kleinerman J, Rice DB. Pathologic changes in the peripheral airways of young cigarette smokers. N Engl F Med 1974;291:755-8.

2 Cosio MG, Hale KA, Niewoehner DE. Morphologic and morphometric effects of prolonged cigarette smoking on the small airways. Am Rev Respir Dis 1980;122:265-71.

3 Adesina AM, Vallyathan V, McQuillen EN, et al. Bronchiolar inflammation and fibrosis associated with smoking. A morphologic cross-sectional population analysis. Am Rev Respir Dis 1991;143:144-9.

4 Seely JE, Zuskin E, Bouhuys A. Cigarette smoking: objective evidence for lung damage in teenagers. Science 1971;172: evidence

5 Myers JL, Veal CF Jr, Shin MS, et al. Respiratory bronchiolitis causing interstitial lung disease. A clinicopathologic study of six cases. Am Rev Respir Dis 1987;135:880-4.

6 Yousem SA, Colby TV, Gaensler EA. Respiratory bronchiolitis-associated interstitial lung disease and its relationship to desquamative interstitial pneumonia. Mayo Clin Proc 1989;64:1373-80.

7 King TE. Respiratory bronchiolitis-associated interstitial lung disease. Clin Chest Med 1993;14:693-8.

8 Chinet T, Dusser D, Labrune S, et al. Lung function declines in patients with pulmonary sarcoidosis and increased respiratory epithelial permeability to $99 \mathrm{mTc}$ DTPA. Am Rev Respir Dis 1990;141:445-9.

9 Wells AU, Rubens MB, du Bois RM, et al. Serial CT in fibrosing alveolitis: prognostic significance of the initial pattern. AfR 1993;161:1159-65.

10 Weiss W. Cigarette smoking and diffuse pulmonary fibrosis. Am Rev Respir Dis 1969;99:67-71.

11 Carilli AD, Kotzen LM, Fischer MJ. The chest roentgenogram in smoking females. Am Rev Respir Dis 1973;107: gram 6 .

12 Remy-Jardin M, Remy J, Gosselin B, et al. Lung parenchymal changes secondary to cigarette smoking pathologic-CT correlations. Radiology 1993;186:643-51.

13 Remy-Jardin M, Remy J, Boulenguez C, et al. Morphologic effects of cigarette smoking on airways and pulmonary parenchyma in healthy adult volunteers: CT evaluation and correlation with pulmonary function tests. Radiology 1993 186:107-15.

14 Holt RM, Schmidt RA, Godwin JD, et al. High resolution $\mathrm{CT}$ in respiratory bronchiolitis-associated interstitial lung disease. F Comput Assist Tomogr 1993;17:46-50.

15 Auerbach O, Hammond EC, Garfinkel L, et al. Relation of smoking and age to emphysema. Whole-lung section study. N Engl f Med 1972;286:853-7.

16 Wright JL, Lawson LM, Pare PD, et al. Morphology of peripheral airways in current smokers and ex-smokers. Am Rev Respir Dis 1983;127:474-7.

17 Friedman PJ, Liebow AA, Sokoloff J. Eosinophilic granuloma of lung. Clinical aspects of primary histiocytosis in the adult. Medicine 1981;60:385-96.

18 Baumgartner KB, Samet JM, Stidley CA, et al. Cigarette smoking: a risk factor for idiopathic pulmonary fibrosis. $A m$ f Respir Crit Care Med 1997;155:242-8. 